\title{
Pengaruh Penggunaan Katalis (Zeolit) Terhadap Kinetic Rate Tar Hasil Pirolisis Serbuk Kayu Mahoni (Switenia Macrophylla)
}

\author{
Dody Candra Kumara*, Widya Wijayanti, Denny Widhiyanuriyawan \\ Teknik Mesin Universitas Brawijaya Indonesia, MT Haryono, 167 - Malang (65145) - \\ Indonesia \\ E-mail: dodyck23@gmail.com
}

\begin{abstract}
This research was conducted to find out the influence of the use of a catalyst (zeolite) against kinetic rate results of tar pyrolysis of sawdust mahogany. research process undertaken experimentally with temperature $523 \mathrm{~K}$ and $873 \mathrm{~K}$ on the heating rate $673 \mathrm{~K} / \mathrm{hour}$. pyrolysis is done for 3 hours with wood powder particle size 0,5-1 $\mathrm{mm}$. before use activated zeolite in advance by means of heated at a temperature of $400{ }^{\circ} \mathrm{C}$ for 1 hour. the results showed the value of kinetic rate tar with zeolites greater than without zeolites, where the value of the kinetic rate equation obtained i.e. $k=$ $185,49 . e^{-2779 / T}$ (heating rate $673 \mathrm{~K} / \mathrm{hour}$ without zeolite) and $k=93,037 . e^{-2034 / T}$ (heating rate $673 \mathrm{~K} /$ hour with zeolite). The results of the validation shows the value addition in the calculation of the volume is already approaching the actual value.
\end{abstract}

Keywords : pyrolysis, zeolite, mahogany, heating rate, temperature, kinetic rate

\section{PENDAHULUAN}

Pirolisis merupakan salah satu teknologi yang telah dikembangkan untuk menghasilkan sumber energi alternatif. Pirolisis disebut juga dengan termolisis yaitu proses dekomposisi kimia bahan organik melalui pemanasan tanpa atau sedikit $\mathrm{O}_{2}$ [1], sehingga material mentah akan mengalami pemecahan struktur kimia menjadi fase gas. Termolisis adalah cara untuk memperoleh hidrokarbon yang merupakan dasar bahan bakar.

Dalam proses pirolisis proses dekomposisi biomassa terpengaruhi oleh beberapa faktor yaitu temperatur, heating rate, waktu tinggal, tekanan, ukuran partikel, kelembaban dan komposisi bahan. Selain itu dalam proses dekomposisi juga bisa menambahkan suatu katalis yang bertujuan untuk mempercepat reaksi dekomposisi dan memperpendek rantai hidrokarbon panjang sehingga mudah untuk di kondensasi menjadi minyak pirolisis / tar [2].

Penelitian dengan menambahkan katalis telah dilakukan oleh beberapa peneliti seperti Beltrame and Carniti [3] membandingkan berbagai macam katalisator yang digunakan dalam pirolisis polietilen. Mereka menemukan bahwa katalisator zeolit merupakan katalisator yang paling efektif, kemudian Ishihara et al [4] melaporkan bahwa pirolisis polietilen menggunakan katalisator silika-alumina dapat memperpendek rantai polimer dan meningkatkan cabang rantai dan Manos et al [5] menemukan proses pirolisis dengan katalisator zeolit menghasilkan produk cair berupa hidrokarbon dengan range $C_{3}-C_{15}$. Selain itu Walendzie et al [6] juga menemukan temperatur optimum pirolisis sampah polyolefin yaitu $410-430^{\circ} \mathrm{C}$ sedangkan pirolisis sampah polyolefin dengan penambahan katalis memiliki temperatur optimum berkisar $390^{\circ} \mathrm{C}$.

Katalis yang dapat digunakan dalam proses pirolisis bermacam-macam jenisnya dan dalam penelitian ini katalis yang digunakan yaitu zeolit, dimana zeolit memiliki tingkat kefektifan yang tinggi. Zeolit merupakan senyawa zat kimia alumino-silikat berhidrat dengan kation natrium, kalium dan barium. Secara umum, zeolit memiliki molekular sruktur yang unik dimana atom silikon dikelilingi oleh 4 atom oksigen sehingga membentuk semacam jaringan dengan pola yang teratur.

Zeolit dalam proses pirolis akan memberikan perambatan suhu yang cepat dan stabil pada biomassa dikarenakan adanya kandungan alumina pada zeolit, sehingga dengan adanya proses tersebut suhu akan memutus rangkaian struktur kimia pada biomassa. Proses pemecahan hidrokarbon terjadi dikarenakan adanya peran struktur pori-pori pada zeolit. Karena pori inilah yang berperan untuk memilah secara spesifik dalam menyerap molekul tertentu dan menolak molekul lainnya. Dalam kaitannya dengan sifat ini, zeolit yang banyak mengandung kation di dalam pori digunakan sebagai pemisah gas dimana molekul dibedakan berdasarkan interaksi elektrostatik 
mereka dengan ion logam. Dengan demikian zeolit dapat memisahkan molekul berdasarkan perbedaan ukuran, bentuk dan polaritas [7].

Selain terjadi proses pemisahan molekul dalam zeolit, pada saat yang bersamaan zeolit juga berperan sebagai penukar kation dimana proses ini akan terjadi pada permukaan dan dalam pori zeolit. Zeolit akan merangsang molekul-molekul yang bermuatan pada gas produk pirolisis, mulamula zeolit akan menarik proton dari gas produk pirolisis akibat beda potensial. Gas produk pirolisis memiliki potensial lebih positif sedangkan zeolit lebih negatif, dimana muatan negatif pada zeolit diakibatkan oleh kandungan aluminium. Dengan adanya perbedaan potensial tersebut proton pindah dari gas produk pirolisis ke zeolit sehingga gas produk pirolisis kekurangan proton atau kelebihan elektron. Sehingga molekulmolekul pada gas produk pirolisis akan mudah pecah dan lebih aktif.

Penelitian ini dilakukan dengan tujuan untuk mengetahui pengaruh katalis terhadap perubahan volume dan seberapa besar nilai kinetic rate tar, dimana persamaan yang digunakan untuk mengetahui nilai kinetic rate tar yaitu persamaan perubahan volume per satuan waktu [8]

$$
\frac{d V}{d t}=k \cdot f\left[\frac{V-V_{\sim}}{V_{o}-V_{\sim}}\right]
$$

dimana $\frac{d V}{d t}$ adalah fraksi perubahan Volume per satuan waktu ( $\mathrm{gr} / \mathrm{menit}$ ), $k$ adalah konstanta laju penambahan volume tar, $V$ adalah volume tar setiap saat, $V_{0}$ adalah volume tar pada awal waktu dan $V_{\sim}$ adalah volume tar pada akhir proses. Selanjutnya, dengan mengganti $k$ yang similar dengan persamaan Arrhenius maka $k$ dapat dinyatakan,

$$
k=A \cdot e^{-E a / R T}
$$

Dimana $\mathrm{k}$ adalah rate constant $\left(\right.$ menit $\left.^{-1}\right)$, Ea adalah energi aktivasi $(\mathrm{kJ} / \mathrm{mol}), \mathrm{R}$ adalah konstanta gas (8314 $\left.\mathrm{J} \mathrm{K}^{-1} \mathrm{~mol}^{-1}\right)$, $\mathrm{T}$ adalah Temperatur (K), A adalah pre-exponential factor (menit ${ }^{-1}$ ) dan pada kondisi nonisothermal penelitian TGA pada heating rate $\beta=d T / d t$, maka persamaan 2 menjadi,

$$
k=\frac{A}{\beta} \cdot e^{-E a / R T}
$$

persamaan 3 dirubah ke bentuk logaritma menjadi persamaan garis lurus untuk mendapatkan nilai energi aktivasi dan preexponential factor,

$$
\begin{gathered}
\ln k=\frac{-E a}{R} \frac{1}{T}+\ln A \\
\downarrow \quad \downarrow \downarrow \downarrow \downarrow \\
y=a x+c
\end{gathered}
$$

\section{METODE PENELITIAN}

Dalam peneltian ini dilakukan secara eksperimental (experimental research) pada temperatur $523 \mathrm{~K}$ dan $873 \mathrm{~K}$ dengan heating rate $673 \mathrm{~K} / \mathrm{jam}$. Katalis yang digunakan yaitu zeolit yang telah diaktivasi dengan perlakuan heat treatment pada temperatur $400^{\circ} \mathrm{C}$ selama 1 jam.

Skema penelitian dapat dilihat pada gambar 1 yang menjelaskan instalasi penelitian beserta keterangan alat-alat pirolisisnya.
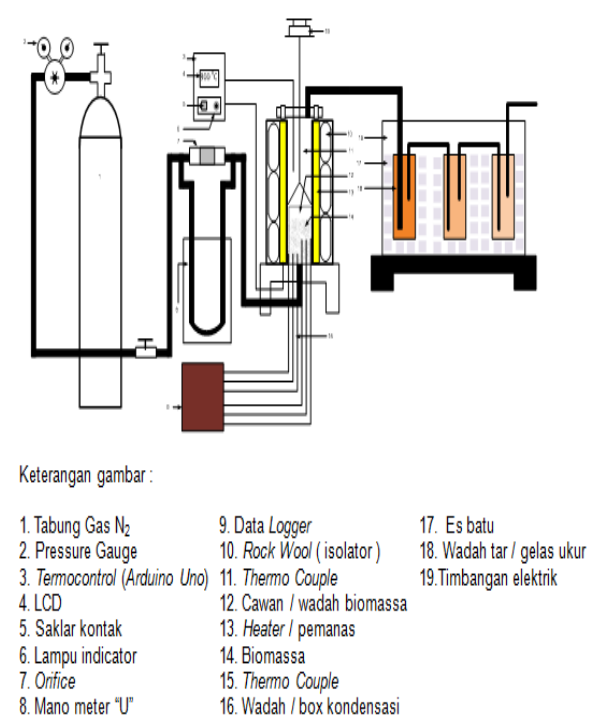

Gambar 1. Instalasi Penelitian

Persiapan awal yang dilakukan sebelum memulai proses pirolisis yaitu membersihkan serbuk kayu mahoni (biomassa) dari kotoran yang ikut terbawa dari tempat pengambilan serbuk, kemudian diayak untuk menyeragamkan ukuran serbuk kayu mahoni 
(biomassa) dengan range 0,5 - $1 \mathrm{~mm}$. Selanjutnya serbuk kayu dikeringkan untuk mengurangi kadar air sampai $<2 \%$,setelah itu sebelum dilakukan proses pirolisis serbuk kayu mahoni (biomassa) ditimbang dengan berat $200 \mathrm{gr}$.

Setelah langkah persiapan selesai dilakukan, serbuk kayu mahoni (biomassa) dimasukkan kedalam reaktor untuk selanjutnya dimasukkan kedalam furnace / tungku pemanas. Gas $\mathrm{N}_{2}$ dialirkan kedalam reactor sampai kadar $\mathrm{O}_{2}$ hilang hingga paling tidak $<2,1 \%$ dari volume reaktor. Setelah itu reaktor dipanaskan pada berbagai temperatur dan heating rate yang telah ditetapkan. Untuk proses menggunakan zeolit, langkah proses yang dilakukan sama dan menambahkan zeolit yang telah diaktivasi sebanyak $100 \mathrm{gr}$ atau $\frac{1}{3}$ dari massa campuran kedalam reaktor sebelum dilakukan proses pirolisis. Selama dalam proses berlangsung, catat volume tar yang terbentuk pada gelas ukur / wadah tar per 3 menit selama waktu pirolisis 180 menit.

\section{HASIL DAN PEMBAHASAN}

Dari Gambar 2 dapat menghitung konstanta laju penambahan volume tar dengan temperatur akhir 523K dengan zeolit pada menit 90 , dimana garis grafik warna biru menandakan kenaikan volume tar pada temperatur akhir $523 \mathrm{~K}$. Untuk melihat jumlah volume tar dapat ditarik garis horizontal kearah kiri. pada gambar 2 menunjukkan pada menit ke 90 didapatkan volume tar sebesar $6 \mathrm{ml}$. Kemudian garis grafik warna merah menandakan kenaikan temperatur proses pirolisis, dimana untuk melihat besar nilai temperatur dapat ditarik garis horizontal kearah kanan. Pada gambar 2 menunjukkan pada menit ke 90 , besar nilai temperatur yaitu 507K.

Dari data volume yang dihasilkan, konstanta laju penambahan volume tar dihitung dengan persamaan 1.

$$
\begin{aligned}
& \frac{d V}{d t}=k \cdot f\left[\frac{V-V_{\sim}}{V_{o}-V_{\sim}}\right] \\
& \frac{6-4}{3}=k\left[\frac{6-18}{6-18}\right] \\
& k=1 \text { menit }^{-1}
\end{aligned}
$$

Untuk perhitungan nilai $k$ seperti contoh juga dilakukan pada menit ke 3 s/d 180 dengan interval 3 menit. Data nilai $k$ yang dihasilkan diubah menjadi In $k$ dan dihubungkan dengan nilai $1 / T$ untuk mendapatkan persamaan linear / garis lurus yang identik dengan persamaan 4. Hubungan linear antara In $k$ dengan $1 / T$ ditunjukkan pada Gambar 3.

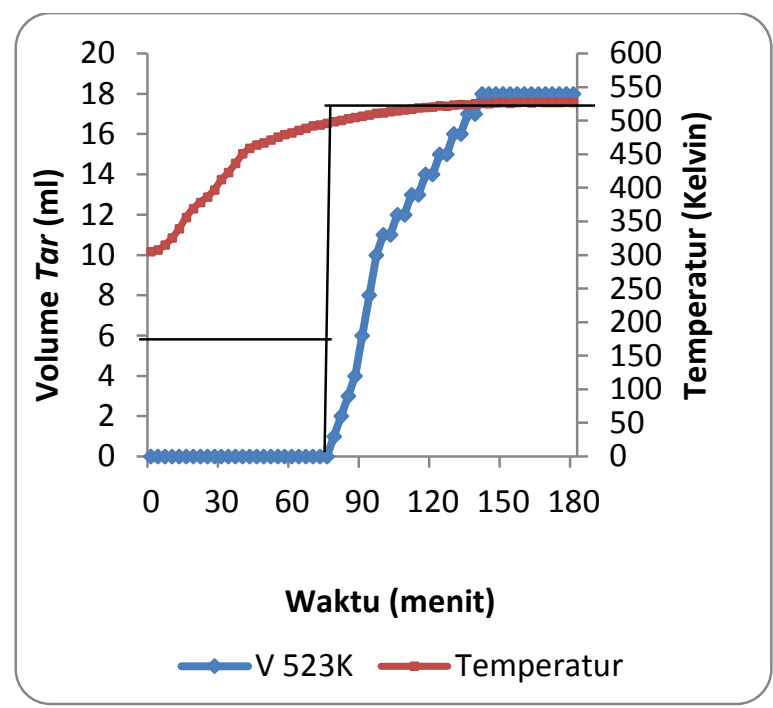

Gambar 2 grafik perubahan volume dan kenaikan temperatur pada temperatur $523 \mathrm{~K}$ dengan zeolit

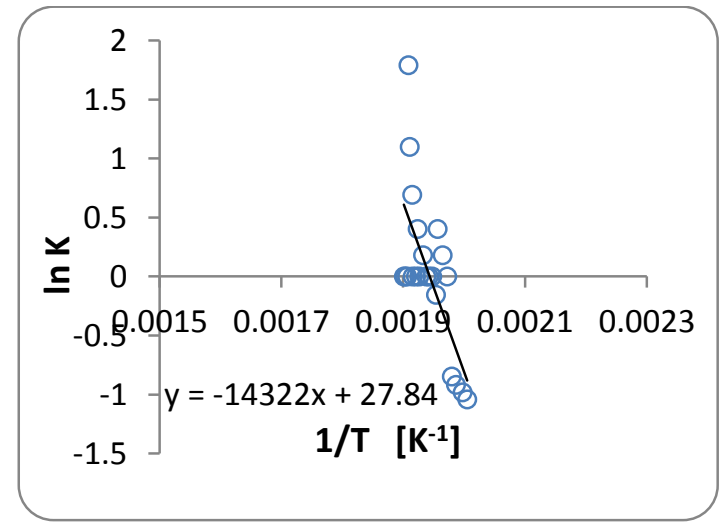

Gambar 3 Kinetik rate pembentukan tar kayu mahoni di temperatur akhir 523K pada heating rate $673 \mathrm{~K} / \mathrm{jam}$ dengan zeolit

Dari Gambar 3 didapatkan sebuah persamaan garis lurus $y=-14322 x+27.84$, 
sehingga hasil perhitungan persamaan 4 mendapatkan persamaan nilai kinetic rate $k=1,232 \times 10^{12} \cdot e^{-14322 / T}$.

Dengan cara yang sama akan didapat persamaan kinetic rate $(k)$ untuk masingmasing temperatur dan heating rate pada Tabel 1 dan 2 .

Tabel 1 Persamaan $k$ untuk Temperatur $523 \mathrm{~K}$ dan $873 \mathrm{~K}$ dengan heating rate 673 $\mathrm{K} / \mathrm{jam}$ tanpa zeolit

\begin{tabular}{cc}
$\begin{array}{c}\text { Temperatur } \\
(\mathrm{K})\end{array}$ & $\begin{array}{c}\text { Heating rate } 673 \mathrm{~K} / \mathrm{jam} \\
\text { tanpa zeolit } \\
\mathrm{k}\left(\text { menit }^{-1}\right)\end{array}$ \\
\hline 523 & $k=2,55 \times 10^{10} \cdot e^{-11524 / T}$ \\
873 & $k=309,82 \cdot e^{-2355 / T}$ \\
\hline
\end{tabular}

Tabel 2 Persamaan $k$ untuk Temperatur $523 \mathrm{~K}$ dan $873 \mathrm{~K}$ dengan heating rate 673 $\mathrm{K} / \mathrm{jam}$ dengan zeolit

\begin{tabular}{cc}
$\begin{array}{c}\text { Temperatur } \\
(\mathrm{K})\end{array}$ & $\begin{array}{c}\text { Heating rate } 673 \mathrm{~K} / \mathrm{jam} \\
\text { dengan zeolit } \\
\mathrm{k}\left(\text { menit }^{-1}\right)\end{array}$ \\
\hline 523 & $k=1,232 \times 10^{12} \cdot e^{-14322 / T}$ \\
873 & $k=342,41 \cdot e^{-3280 / T}$ \\
\hline
\end{tabular}

Tabel 3 Nilai $1 / T$ dan In $k$ untuk persamaan kinetic rate $(\mathrm{k})$ pada heating rate $673 \mathrm{~K} / \mathrm{jam}$ dengan zeolit maupun tanpa zeolit

\begin{tabular}{cccc}
\hline & & $\begin{array}{c}\text { Heating } \\
\text { rate 673 } \\
\text { K/jam } \\
\text { tanpa } \\
\text { zeolit } \\
\text { (K) }\end{array}$ & $\begin{array}{c}\text { Heating } \\
\text { rate 673 } \\
\text { K/jam } \\
\text { dengan } \\
\text { zeolit } \\
\text { In k }\end{array}$ \\
\hline 523 & 0.001912 & -0.37442 & 0.45568 \\
873 & 0.001145 & 1.76005 & 2.07884 \\
\hline
\end{tabular}

Dari persamaan kinetic rate $(\mathrm{k})$ masingmasing temperatur dan heating rate dengan zeolit maupun tanpa zeolit (tabel 1 dan 2) dapat dihitung persamaan kinetic rate $(\mathrm{k})$ untuk proses pirolisis dengan zeolit maupun tanpa zeolit, dengan cara memasukkan nilai temperatur pada persamaan k. Hasil perhitungan nilai k kembali dijadikan dijadikan In $\mathrm{k}$ dan digambarkan ke grafik hubungan Ink dengan $1 / \mathrm{T}$ seperti terlihat pada tabel 3 , Gambar 4 dan 5.

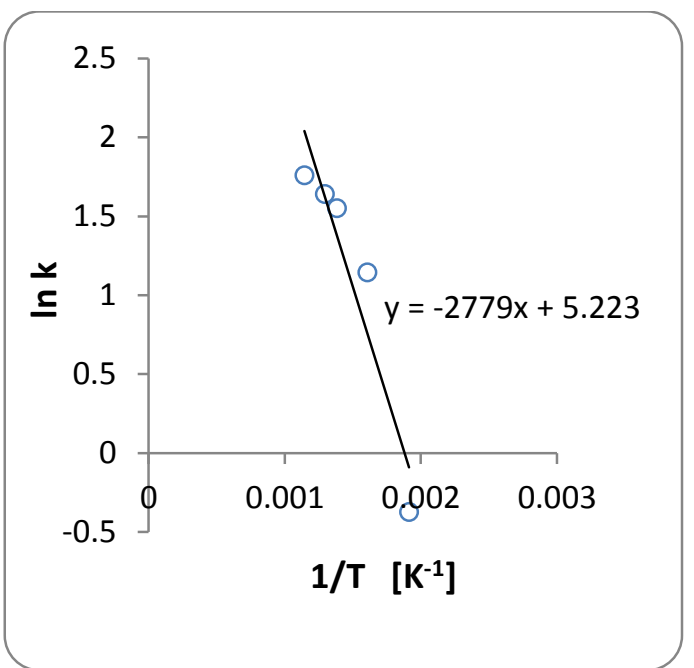

Gambar 4 Kinetik rate pembentukan tar pada heating rate $673 \mathrm{~K} / \mathrm{jam}$ tanpa zeolit

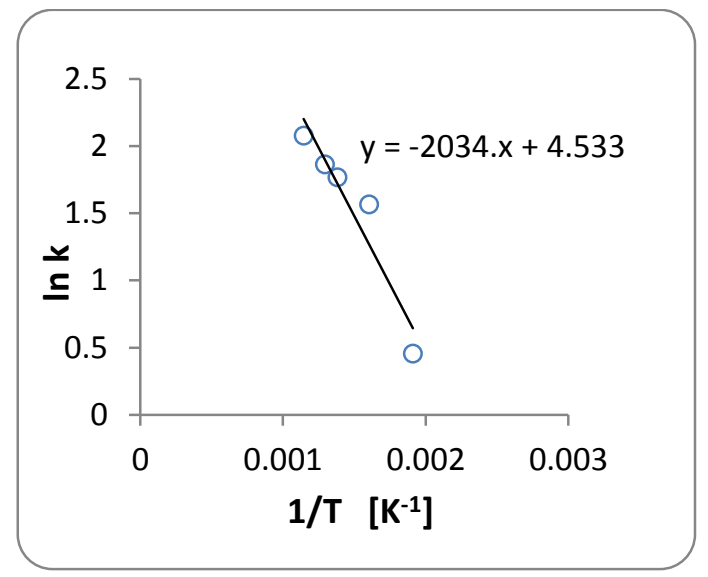

Gambar 5 Kinetik rate pembentukan tar pada heating rate $673 \mathrm{~K} / \mathrm{jam}$ dengan zeolit Dari gambar 4 dan 5 didapat persamaan linear untuk:

- Heating rate $673 \mathrm{~K} / \mathrm{jam}$ tanpa zeolit $y=-2779 x+5,223$

- Heating rate $673 \mathrm{~K} / \mathrm{jam}$ dengan zeolit $y=-2034 x+4,533$

Dari persamaan linear untuk proses pirolisis dengan zeolit maupun tanpa zeolit, 
akan didapat persamaan kinetic rate $(k)$, energi aktivasi (Ea) dan pre-exponential factor (A) seperti terlihat pada tabel 4.

Tabel 4 Persamaan kinetic rate $(k)$, nilai Ea dan $A$

\begin{tabular}{|c|c|c|c|}
\hline $\begin{array}{l}\text { Heating } \\
\text { rate } \\
\text { (K/jam) }\end{array}$ & $\begin{array}{l}\text { Persamaan } \\
\text { kinetic rate }(k) \\
\left(\text { menit }^{-1}\right)\end{array}$ & $\underset{\left(\mathrm{kj} \cdot \mathrm{mol}^{-1}\right)}{\mathrm{Eg}}$ & $\underset{\text { (menit }}{\mathrm{A}}$ \\
\hline $\begin{array}{l}673 \\
\text { tanpa } \\
\text { zeolit }\end{array}$ & $k=185,49 \cdot e^{-277 \% / T}$ & 23104,61 & 2080,58 \\
\hline $\begin{array}{l}673 \\
\text { dengan } \\
\text { zeolit }\end{array}$ & $k=93,037 \cdot e^{-2034 / \tau}$ & 16910,68 & 1043,57 \\
\hline
\end{tabular}

Selanjutnya dari persamaan kinetic rate (k) untuk proses pirolisis dengan zeolit maupun tanpa zeolit akan didapatkan nilai $\mathrm{k}$ seperti terlihat pada Tabel 5.

Tabel 5 Nilai $k$ untuk proses pirolisis dengan zeolit maupun tanpa zeolit

\begin{tabular}{ccc}
\hline $\begin{array}{c}\text { Temp. } \\
\text { (K) }\end{array}$ & $\begin{array}{c}\text { Heating rate } \\
673 \mathrm{~K} / \mathrm{jam} \\
\text { tanpa zeolit } \\
\text { Nilai k }\left(\text { menit }^{-1} \text { ) }\right.\end{array}$ & $\begin{array}{c}\text { Heating rate } \\
673 \mathrm{~K} / \mathrm{jam} \\
\text { dengan zeolit } \\
\text { Nilai k }\left(\text { menit }^{-1} \text { ) }\right.\end{array}$ \\
\hline 523 & 0,9134 & 1,9039 \\
873 & 7,6885 & 9,0531 \\
\hline
\end{tabular}

Dari Tabel 5 dapat dilihat bahwa nilai kinetic rate untuk proses pirolisis dengan menggunakan zeolit lebih besar dari pada proses tanpa zeolit, sehingga teori tentang katalis untuk mempercepat proses dekomposisi pada biomassa adalah benar. Selanjutnya dilakukan pengecekan pada perhitungan nilai kinetic rate dengan cara membandingkan besar perubahan volume tar secara hitungan dengan volume tar pengujian.

Untuk memvalidasi penambahan volume tar dengan persamaan nilai $\mathrm{k}$ yang didapat dengan penambahan volume tar pengujian, maka kita masukkan lagi ke perhitungan awal, mulai menit ke $3 \mathrm{~s} / \mathrm{d} 180$ dengan interval 3 menit pada persamaan 1 .

$\frac{V_{3}-0}{3}=93,037 \cdot e^{-2034 / T}\left[\frac{V_{3}-18}{0-18}\right]$

Sehingga dengan perhitungan tersebut didapat nilai perubahan volume tar dengan cara perhitungan, yang mana jika digambarkan pada grafik dapat dilihat pada gambar 6 dan 7.

Dari gambar 6 dan 7 dapat dilihat semakin tinggi temperatur, volume tar juga mengalami peningkatan, dimana hal ini terjadi karena adanya proses dekomposisi atau pemutusan ikatan kimia pada biomassa. Reaksi pertama yaitu reaksi primer merupakan reaksi dekomposisi yang menghasilkan produk berupa char ${ }_{1}$, tar ${ }_{1}$ dan gas 1 . Reaksi ini berlangsung pada temperatur $250^{\circ} \mathrm{C}-450^{\circ} \mathrm{C}$ dan reaksi kedua / tambahan yaitu reaksi sekunder, dimana hasil dari reaksi ini yaitu sebagian dari tar ${ }_{1}$ menjadi gas2, reaksi ini berlangsung pada temperatur $450^{\circ} \mathrm{C}-800^{\circ} \mathrm{C}$, sehingga semakin banyak gas dan tar yang terbentuk [9].

untuk melihat besar pengaruh dari zeolit dapat dilihat dari waktu pembentukan tar, dimana waktu pembentukan tar pada proses pirolisis dengan menggunakan zeolit jauh lebih cepat dibanding tanpa menggunakan zeolit, selain itu nilai perubahan volume tar secara perhitungan mendekati nilai volume tar pengujian. 


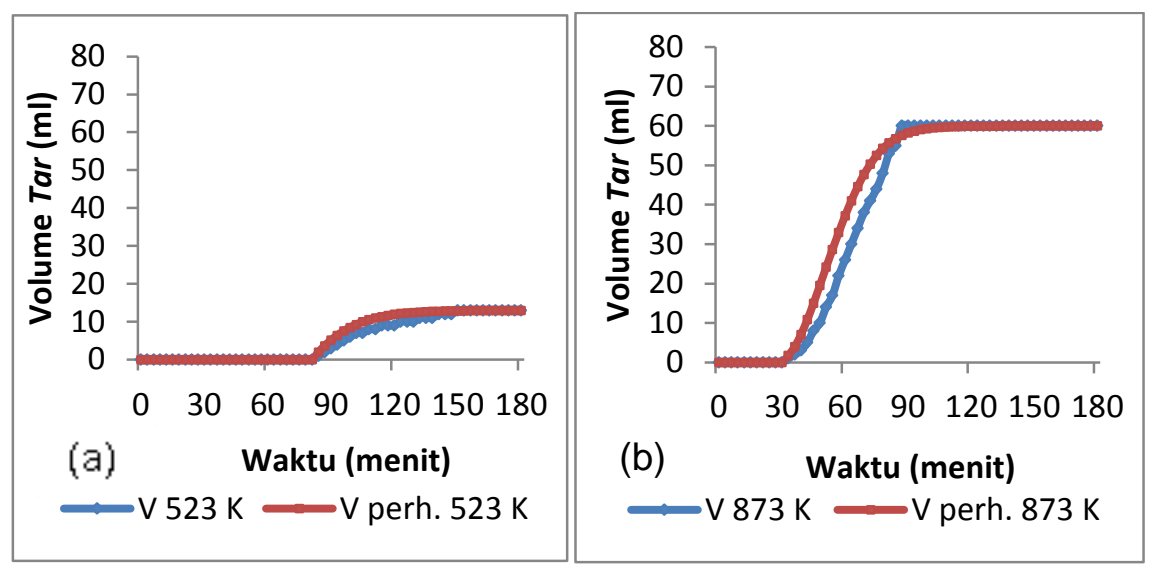

Gambar 6 Grafik penambahan volume tar pengujian dengan penambahan volume tar hasil perhitungan persamaan kinetik pada temperatur 523K (a) dan $873 \mathrm{~K}$ (b) heating rate $673 \mathrm{~K} /$ jam tanpa zeolite

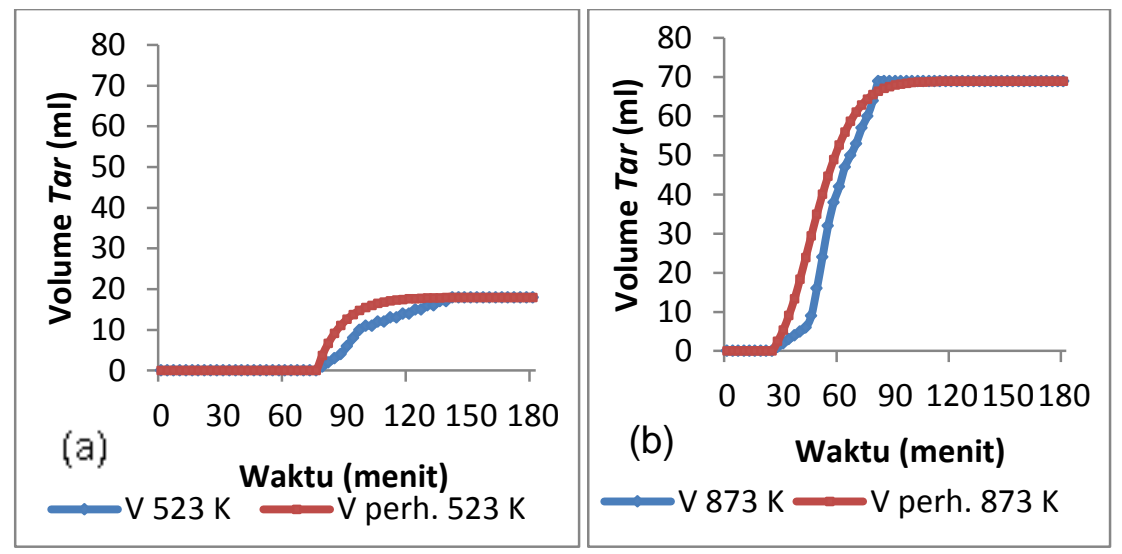

Gambar 7 Grafik penambahan volume tar pengujian dengan penambahan volume tar hasil perhitungan persamaan kinetik pada temperatur 523K (a) dan $873 \mathrm{~K}$ (b) heating rate $673 \mathrm{~K} / \mathrm{jam}$ dengan zeolit

\section{KESIMPULAN}

Dari penelitian yang dilakukan dapat diambil kesimpulan yaitu

- Temperatur dan penggunaan katalis (zeolit) mempunyai pengaruh yang besar dalam proses pirolisis, dimana semakin tinggi temperatur maka volume tar semakin meningkat dan nilai kinetic rate semakin besar, demikian pula dengan pengaruh katalis (zeolit) pada proses pirolisis.

- Nilai kinetic rate tar pada proses pirolisis dengan menggunakan zeolit lebih besar dibanding tanpa zeolit dan setelah dilakukan validasi nilai penambahan volume tar hitungan mendekati nilai penambahan volume tar secara pengujian.

\section{DAFTAR PUSTAKA}

[1] Fatimah, Is. 2004. Pengaruh laju pemanasan terhadap komposisi Biofuel hasil pirolisis serbuk kayu. Jurnal LOGIKA, vol 1, No. 1

[2] Danarto, Y.C., Budi Utomo, P., dan Sasmita , F., 2010. Pirolisis Limbah Serbuk Kayu dengan Katalisator Zeolit. Prosiding Seminar Nasional Teknik Kimia

[3] Beltrame, P. and Carniti, P., 1989, Catalytic Degradation of Polymer: Part II 
- Degradation of Polyethylene, Polym. Deg. Stabil., 26, 209-220

[4] Ishihara, Y., Nanbu, H., Saido, K., Ikemura, T., and Takesue, T., 1992 "Mechanism for Gas Formation in Polyethylene Catalytic Decomposition" Nihon Univ., Coll. Sci. Technology, dep. Industrial Chemistry, Chiyoda-Ku, Tokyo 101, Japon, vol. 33, no.16, pp. 34823486. ISSN 0032-3861

[5] Manos, G., Garforth, A., and Dwyer, J., 2000, Catalyst Degradation of High Density Polyethylene Over Different Zeolite Structure, Ind. Eng.Chem. Res., 39, 1198

[6] Walendzie, J. and Steininger, M., 2001, Catal. Today, 65, 323
[7] Fatimah, Is. 2013. Kinetika Kimia. Edisi pertama, penerbit Graha IImu. ISBN : 978-979-756-919-8

[8] Slopiecka, Katarzyna., Bartoci, Pietro., \& Fantozzi, $\quad$ Francesco., 2011 Thermogravimetric Analysis and Kinetic Study of Poplar Wood Pyrolysis : University of Perugia

[9] Tanoue, Ken-Iciro., Hinauchi, Tatsuya., OO, Thaung., Nishimura, Tatsuo., Taniguchi, Miki., and Sasauchi, KenIchi., 2007 Modeling of heterogeneous chemical reactions caused in pyrolysis of biomass particles, Japan : Advanced Powder Technol., Vol. 18, No. 6, pp. 825-84 